\title{
RNAi-mediated Soybean mosaic virus (SMV) resistance of a Korean Soybean cultivar
}

\author{
Hye Jeong Kim ${ }^{1} \cdot$ Mi-Jin Kim ${ }^{2} \cdot$ Jung Hun Pak ${ }^{1} \cdot$ Hyun Hee $\mathbf{I m}^{1}$ • \\ Dong Hee $\mathrm{Lee}^{3} \cdot$ Kook-Hyung Kim ${ }^{4} \cdot \mathrm{Jai}^{-H e o n} \mathrm{Lee}^{1} \cdot$ Doh-Hoon Kim ${ }^{1}$. \\ Hong Kyu Choi ${ }^{1} \cdot$ Ho Won Jung ${ }^{1}$ Y Young-Soo Chung ${ }^{1}$
}

Published online: 13 July 2016

(c) Korean Society for Plant Biotechnology and Springer Japan 2016

\begin{abstract}
Soybean [Glycine max (L.) Merr.] is an important crop for vegetable oil production, and is a major protein source worldwide. Because of its importance as a crop, genetic transformation has been used extensively to improve its valuable traits. Soybean mosaic virus (SMV) is one of the most wellknown viral diseases affecting soybean. Transgenic soybean plants with improved resistance to SMV were produced by introducing HC-Pro coding sequences within RNA interference (RNAi) inducing hairpin construct via Agrobacteriummediated transformation. During an experiment to confirm the response of transgenic plants $\left(\mathrm{T}_{2}\right)$ to $\mathrm{SMV}$ infection, no $\mathrm{T}_{2}$ plants from lines \#2 (31/31), \#5 (35/35) or \#6 (37/37) exhibited any SMV symptoms, indicating strong viral resistance $(\mathrm{R})$, whereas NT (non-transgenic wild type) plants and those from lines \#1, \#3 and \#4 exhibited mild mosaic (mM) or mosaic (M) symptoms. The northern blot analysis showed that three resistant lines (\#2, \#5 and \#6) did not show the detection of viral RNA accumulation while NT, EV (transformed with empty vector carrying only Bar) and lines \#1, \#3 and \#4 plants were
\end{abstract}

Electronic supplementary material The online version of this article (doi:10.1007/s11816-016-0402-y) contains supplementary material, which is available to authorized users.

Young-Soo Chung

chungys@dau.ac.kr

1 Department of Genetic Engineering, College of Natural Resources and Life Science, Dong-A University, Busan 604-714, Republic of Korea

2 Biotechnology Institute, Nongwoo Bio Co., LTD, Yeoju-si, Gyeonggi-do 469-885, Republic of Korea

3 Genomine Advanced Biotechnology Research Institute, Genomine Inc., Pohang 790-834, Republic of Korea

4 Department of Agricultural Biotechnology, Seoul National University, Seoul 151-921, Republic of Korea detected. $\mathrm{T}_{3}$ seeds from SMV-inoculated $\mathrm{T}_{2}$ plants were harvested and checked for changes in seed morphology due to viral infection. $T_{3}$ seeds of lines \#2, \#5 and \#6 were clear and seed coat mottling was not present, which is indicative of SMV resistance. RT-PCR and quantitative real-time PCR showed that $\mathrm{T}_{3}$ seeds from the $\mathrm{SMV}$-resistant lines \#2, \#5 and \#6 did not exhibit any detection of viral RNA accumulation (HC-Pro, $C P$ and $C I$ ), while the viral RNA accumulation was detected in SMV-susceptible lines \#1, \#3 and \#4 plants. During the greenhouse test for viral resistance and yield components, $\mathrm{T}_{3}$ plants from the SMV-inoculated transgenic lines \#2, \#5 and \#6 showed viral resistance $(\mathrm{R})$ and exhibited a more favorable average plant height, number of nodes per plant, number of branches per plant, number of pods per plant and total seed weight with statistical significance during strong artificial SMV infection than did other plant lines. In particular, the SMVresistant line \#2 exhibited superior average plant height, pod number and total seed weight with highly significance. According to our results, RNAi induced by the hairpin construct of the SMV HC-Pro sequence effectively confers much stronger viral resistance than did the methods used during previous trials, and has the potential to increase yields significantly. Because of its efficiency, the induction of RNAi-mediated resistance will likely be used more frequently as part of the genetic engineering of plants for crop improvement.

Keywords Soybean - Soybean mosaic virus (SMV) · Agrobacterium-mediated transformation · Viral resistance . HC-Pro

\section{Introduction}

Soybean [Glycine max (L.) Merr.] is a major crop that produces the best vegetable oil and protein for use in food and beverage production worldwide. Because of its 
importance as a crop, genetic transformation techniques have been used extensively to improve the crop's valuable traits (Zeng et al. 2004; Seo et al. 2009). Soybean mosaic virus (SMV), a member of the family Potyviridae, which has a positive-sense-stranded RNA genome of approximately $10 \mathrm{~kb}$, is one of the most well-known viral diseases affecting soybean. The symptoms of SMV infection in soybean plants and seeds include the presence of a mosaic pattern on the plant's leaves, leaf curling, necrosis, chlorosis and seed mottling. In particular, infected soybean plants may result in yield losses because of the noticeable reduction in the number of seeds produced by infected plants (Seo et al. 2009; Cho and Goodman 1979; Steinlage et al. 2002; Hobbs et al. 2003; Gunduz et al. 2004). The transmission of SMV occurs in soybean fields because not only does the virus spread from parent to progeny, it also spreads via the movement of more than 30 different kinds of aphid species, which may lead to secondary spreading of the virus (Steinlage et al. 2002; Hill et al. 1980; Halbert et al. 1981; Jagtap et al. 2011).

Improving the genetic resistance of soybean cultivars has been considered the most effective means of managing SMV damage to soybean plants. Three independent SMVresistant (R) gene loci, including Rsv1, Rsv3 and Rsv4, have been identified in soybean cultivars PI 96983, L29 and V94-5152, respectively. These loci may confer resistance to the disease caused by seven SMV strains (G1-G7). $R s v 1, R s v 3$ and $R s v 4$ are resistant to strains G1-G6, G5-G7 and G1-G7, respectively (Gunduz et al. 2004; Lim 1985; Hayes et al. 2000; Zheng et al. 2006; Gagarinova et al. 2008). Using conventional breeding methods to produce SMV-resistant cultivars is a laborious and time-consuming procedure, and is often accompanied by the introgression of undesirable traits via the cross. To overcome the limitations of conventional breeding, genetic transformation can be a good method of improving virus resistance in soybean (Jagtap et al. 2011; Furutani et al. 2006; Kim et al. 2013; Gao et al. 2015).

Soybean transgenic plants with various useful genes have been developed using Agrobacterium-mediated transformation system based on the cotyledonary-node $(\mathrm{CN})$ method (Hinchee et al. 1988). Recently, the system has been improved and simplified by incorporating the use of halfseed explants (Paz et al. 2006). Using additional treatments, such as a mixture of thiol compounds, sonication and a vacuum resulted in positive improvements in transformation efficiency (Meurer et al. 1998; Olhoft et al. 2003).

Plants have evolved to resist viral invasion. RNA silencing is known to be an adaptive antiviral mechanism that protects plants against viral infection. Plant viruses have a RNA-based genome and are known inducers of RNA silencing and targets of posttranscriptional gene silencing (PTGS) (Jagtap et al. 2011; Roth et al. 2004;
Rahman et al. 2008; Soitamo et al. 2011). However, several viruses encode proteins that suppress RNA silencing. Helper-component proteinase (HC-Pro), a potyvirus RNA silencing suppressor, is a multifunctional protein encoded by plant viruses and involved in different steps of the viral infection cycle, replication, aphid transmission and viral systemic and cell-to-cell movement in plants. Remarkably, HC-Pro has been identified as a suppressor of PTGS that prevents silencing by blocking the accumulation of siRNAs and enhances the accumulation of heterologous viruses (Roth et al. 2004; Kasschau and Carrington 2001; Mlotshwa et al. 2002; Plisson et al. 2003; Lim et al. 2005). Because of the efficiency of its RNA interference (RNAi), it is one of the most exciting biotechnological approaches to the functional analysis of genes and antiviral mechanisms (Rahman et al. 2008; Matthew 2004; Tenllado et al. 2004). The resistance of papaya, plum, cassava, bean, sugar beet, tobacco, rice, tomato, etc. to viruses is produced by RNA-mediated silencing (Frizzi and Huang 2010). A nonbruising trait can also be introduced via the same strategy, when the reduction of polyphenol oxidase is induced by RNAi (Okanagan Specialty Fruits Inc., Canada, 2014). Therefore, RNAi is an important tool for knocking down targeted genes and silencing specific plant traits. If viral diseases affecting plants can be controlled, crop plants can be protected from the damage caused by viruses and insects (Jagtap et al. 2011; Matthew 2004; Tenllado et al. 2004).

In our previous study, most transgenic lines transformed with $S M V$-CP using RNAi were susceptible to SMV. Only a few plants exhibited SMV resistance in the $\mathrm{T}_{1}$ generation. In addition, resistance decreased continuously in the successive generation (Kim et al. 2013). To improve resistance against SMV, we produced new transgenic soybean plants by introducing $\mathrm{HC}$-Pro coding sequences within a RNAi inducing hairpin construct via Agrobacterium-mediated transformation system, and examined their response to viral infection. The inhibition of HC-Pro expression enhanced viral resistance after viral infection, compared to the resistance of virus-susceptible non-transgenic plants.

\section{Materials and methods}

\section{Vector construction and Agrobacterium preparation}

HC-Pro gene of SMV strain G7H was provided by Dr. K.H. Kim (GenBank: AY294045.1, Seoul National University, Korea) and a partial fragment of $306 \mathrm{bp}$ (Fig. 1a) was amplified by PCR using HC-Pro-F primer (5'-CACCATGCCTCCTAATGTGGAGAA- $3^{\prime}$ ) and $H C$ Pro-R primer (5'-ACGCACAATCTCCAGTGATGTCTG$3^{\prime}$ ). The plasmid, pB7GWIWG2(I)-HC-Pro (Fig. 1b) was constructed and transformed into Agrobacterium 
a ATGCCTCCTAATGTGGAGAATCATGAATGCACCATTGATTTCACAAATGAACAATGTGGTGAACTGGCAGCGGCAATAAGCCAG TCAATTTTTCCAGTTAAGAAACTATCATGCAAGCAATGTCGGCAGCACATTAAGCACCTCAGTTGGGAGGAGTATAAACAATTCC TCTTGGCTCATATGGGCTGCCATGGGACCGAATGGGAAACTTTCCAAGAAATTGACGGCATGAAGTATGTGAAGAGAGTGATTG AGACATCAACTGCGGAAAACGCAAGTCTGCAGACATCACTGGAGATTGTGCGT

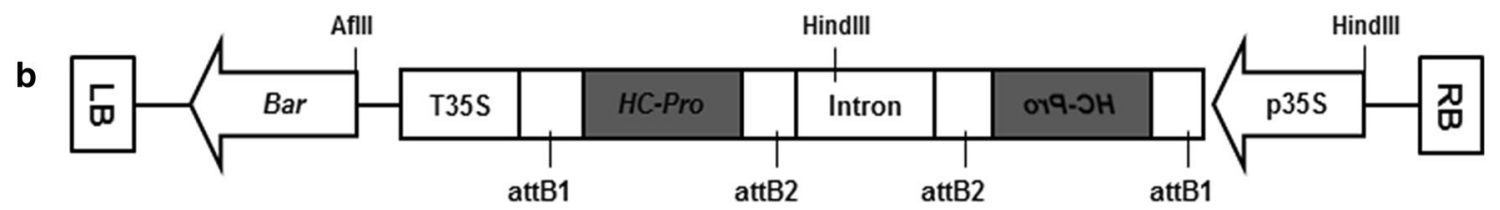

Fig. 1 Sequence of HC-Pro and vector used for soybean transformation. a Partial sequence of $H C$-Pro of soybean mosaic virus strain $\mathrm{G} 7 \mathrm{H}$, used for soybean transformation. b Schematic representation of the HC-Pro and Bar genes used for soybean transformation. Amplified partial HC-Pro was subcloned into RNAi

tumefaciens strain EHA105 (Karimi et al. 2002), following the protocol described by Kim et al. (2013).

\section{Soybean transformation}

Seeds were prepared using mature soybean seeds of Korean cultivar Kwangan. Soybean seeds were sterilized for $20 \mathrm{~h}$ using chlorine gas produced by mixing $5 \mathrm{~mL}$ of $12 \mathrm{~N} \mathrm{HCl}$ and $95 \mathrm{~mL}$ of $12 \%$ sodium hypochlorite in a tightly sealed desiccator (Paz et al. 2006; Di et al. 1996). One day before inoculation, 100-120 seeds were surface sterilized again using $1 \%$ sodium hypochlorite mixed with Tween 20 by Tube Tumbler Rotating Mixer (Select BioProducts, USA) and soaked in distilled water overnight at room temperature. Previously prepared Agrobacterium stock (1 mL) was cultured in $200 \mathrm{~mL}$ liquid YEP medium containing $50 \mathrm{mg}$ $\mathrm{L}^{-1}$ spectinomycin and $25 \mathrm{mg} \mathrm{L}^{-1}$ rifampicin for $20 \mathrm{~h}$ at $28{ }^{\circ} \mathrm{C}, 250 \mathrm{rpm}$ until $\mathrm{OD}_{600}$ reached between 0.6 and 0.8 . For inoculation, Agrobacterium culture was centrifuged for $15 \mathrm{~min}$ at $20^{\circ} \mathrm{C}, 7000 \mathrm{rpm}$. The cell pellet was re-suspended in $15 \mathrm{~mL}$ liquid CCM (Co-Cultivation Medium) containing $0.32 \mathrm{~g} \mathrm{~L}^{-1}$ B5 salt with B5 vitamins, $4.26 \mathrm{~g}$ $\mathrm{L}^{-1} \mathrm{MES}, 3 \%$ sucrose, $1.67 \mathrm{mg} \mathrm{L}^{-1}$ 6-BA, $0.25 \mathrm{mg} \mathrm{L}^{-1}$ $\mathrm{GA}_{3}, 0.2 \mathrm{mM}$ acetosyringone, $3.3 \mathrm{mM}$ L-cysteine, $1.0 \mathrm{mM}$ sodium thiosulfate and $1.0 \mathrm{mM}$ DTT, pH 5.4. The $15 \mathrm{~mL}$ liquid CCM was also used as a dipping solution. The cotyledons were separated by a longitudinal cut, and the seed coat was removed. The embryonic axis found at the junctions between the hypocotyl and the cotyledon was excised to obtain the half-seed explant (Paz et al. 2006) and the junction area was wounded eight times using a No. 11 scalpel blade (Feather, Japan), and then treated with the dipping solution. About 50 half-seed explants were immersed in $15 \mathrm{~mL}$ Agrobacterium suspension, treated with sonication for $20 \mathrm{~s}$ and a vacuum for $30 \mathrm{~s}$, then inoculated for $30 \mathrm{~min}$ at room temperature. After inoculation, explants were placed adaxial side down on CCM containing $5 \mathrm{~g} \mathrm{~L}^{-1}$ agar overlaid with filter paper
pB7GWIWG2(I) vector for soybean transformation. LB/RB, left/ right T-DNA border sequence; p35S/T35S, CaMV (cauliflower mosaic virus) $35 \mathrm{~S}$ promoter/terminator; Bar, coding region of the DL-phosphinothricin resistance gene. The AfII and HindIII restriction enzyme sites are also marked

(Advantec, Japan). The co-cultivation was continued for 5 days at $24{ }^{\circ} \mathrm{C}$ under an $18 \mathrm{~h}$ photoperiod. After 5 days of co-cultivation, half-seed explants were briefly washed in liquid SIM (Shoot Induction Medium) containing $3.2 \mathrm{~g}$ $\mathrm{L}^{-1}$ B5 salt with $\mathrm{B} 5$ vitamins, $0.6 \mathrm{~g} \mathrm{~L}^{-1} \mathrm{MES}, 3 \%$ sucrose, $1.67 \mathrm{mg} \mathrm{L}^{-1} \mathrm{BA}, 250 \mathrm{mg} \mathrm{L}^{-1}$ cefotaxime, $100 \mathrm{mg} \mathrm{L}^{-1}$ ticarcillin and $50 \mathrm{mg} \mathrm{L}^{-1}$ vancomycin for $10 \mathrm{~min}$. The explants were embedded in SIM containing $5.4 \mathrm{~g} \mathrm{~L}^{-1}$ agar with the flat side up. Shoot induction was carried out for 14 days at $24{ }^{\circ} \mathrm{C}$ under an 18 -h photoperiod in a tissue culture room. Explants were also transferred to fresh SIM containing $10 \mathrm{mg} \mathrm{L}^{-1}$ DL-phosphinothricin (PPT) for 14 days. After 4 weeks of shoot induction, explants were transferred to SEM (Shoot Elongation Medium) containing $4.4 \mathrm{~g} \mathrm{~L}^{-1} \mathrm{MS}$ salt with B5 vitamins, $0.6 \mathrm{~g} \mathrm{~L}^{-1} \mathrm{MES}, 3 \%$ sucrose, $5.4 \mathrm{~g} \mathrm{~L}^{-1}$ agar, $0.5 \mathrm{mg} \mathrm{L}^{-1}$ $\mathrm{GA}_{3}, 50 \mathrm{mg} \mathrm{L}^{-1}$ asparagine, $100 \mathrm{mg} \mathrm{L}^{-1}$ L-pyroglutamic acid, $0.1 \mathrm{mg} \mathrm{L}^{-1} \mathrm{IAA}, 1 \mathrm{mg} \mathrm{L}^{-1}$ zeatin riboside, $250 \mathrm{mg}$ $\mathrm{L}^{-1}$ cefotaxime, $100 \mathrm{mg} \mathrm{L}^{-1}$ ticarcillin, $50 \mathrm{mg} \mathrm{L}^{-1}$ vancomycin and $5 \mathrm{mg} \mathrm{L}^{-1} \mathrm{PPT}, \mathrm{pH}$ 5.6. Explants were transferred to fresh SEM every 2 weeks, and brown parts of shoots were cut using a No. 15 scalpel blade. During the shoot elongation, elongated shoots were cut using a No. 11 scalpel blade, dipped in $1 \mathrm{mg} \mathrm{L}^{-1} \mathrm{IBA}$ for $3 \mathrm{~min}$, then transferred to RM (rooting medium) containing $4.4 \mathrm{~g} \mathrm{~L}^{-1}$ MS salt with $\mathrm{B} 5$ vitamins, $0.6 \mathrm{~g} \mathrm{~L}^{-1} \mathrm{MES}, 3 \%$ sucrose, $4.4 \mathrm{~g} \mathrm{~L}^{-1}$ agar, $25 \mathrm{mg} \mathrm{L}^{-1}$ asparagine, $25 \mathrm{mg} \mathrm{L}^{-1} \mathrm{~L}-\mathrm{py}-$ roglutamic acid, $50 \mathrm{mg} \mathrm{L}^{-1}$ cefotaxime, $50 \mathrm{mg} \mathrm{L}^{-1}$ ticarcillin and $50 \mathrm{mg} \mathrm{L}^{-1}$ vancomycin, $\mathrm{pH}$ 5.6. Rooted plantlets were rinsed with water to wash off the agar medium and transplanted to soil containing a mixture of Biosoil (Hongnong Horticulture, Korea) and vermiculite in a ratio of $3: 1$ in a magenta jar (SPL, Korea) for 1-3 weeks. $\mathrm{T}_{0}$ plants were then transplanted to large pots and grown in a greenhouse. An herbicide assay was used to determine resistance by screening $T_{0}$ plants with two trifoliates to identify putative transformants that expressed Bar. The upper surface of a leaf was painted across the midrib using 
a brush with $100 \mathrm{mg} \mathrm{L}^{-1}$ PPT mixed with Tween 20 . The response to the herbicide was observed at 3-5 days after PPT painting. Twenty $T_{0}$ plants resistant to PPT were grown in a greenhouse and seeds were harvested.

\section{Confirmation of transgene in transgenic plants}

Polymerase chain reaction (PCR) analysis was conducted to detect the introduced gene in NT and transgenic plants. Total genomic DNA was extracted using cetyltrimethylammonium bromide. To identify plants with HC-Pro insertion, the DNAs between HC-Pro (forward primer, $5^{\prime}$ GCAGCGGCAATAAGCCAGTCAATT- ${ }^{\prime}$ ) and the intron (reverse primer, 5'-TGATGGCCATAGGGGTTTAGAT GC- $3^{\prime}$ ) and between the intron (forward primer, $5^{\prime}$ GCATCTAAACCCCTATGGCCATCA- $3^{\prime}$ ) and HC-Pro (reverse primer, 5'-GCAGCGGCAATAAGCCA GTCAATT- $3^{\prime}$ ) were amplified. Bar (forward primer, 5' ATGAGCCCAGAACGACGCCC- $3^{\prime}$ and reverse primer, $5^{\prime}$-TCAGATTTCGGTGACGGGCA-3') and DNA from the left border (LB) to Bar (forward primer, 5' TGGCTGGTGGCAGGATATATTGTG- $3^{\prime}$ and reverse primer, 5'-AGACAAGCACGGTCAACTTCCGTA-3') were also amplified. PCR was performed using KOD FX polymerase (TOYOBO, Osaka, Japan) according to the manufacturer's instructions. The PCR reactions were conducted using a thermal cycler (Bio-Rad, USA).

For the Southern blot analysis, $15 \mu \mathrm{g}$ of genomic DNA from NT and transgenic plants were digested overnight by HindIII, fractionated on $0.8 \%$ agarose gel by electrophoresis, then transferred onto Hybond $\mathrm{N}+$ nylon membrane (Amersham Pharmacia, USA). Hybridization, washing and detection were performed with a digoxigenin (DIG)-labeled DNA probe and a chemiluminescence system (Roche, Germany), according to the manufacturer's instructions. The DIG-labeled probe was prepared via PCR amplification with the Bar forward primer (5'AACTTCCGTACCGAGCCGCA- $3^{\prime}$ ) and Bar reverse primer (5'-TCGTAGGCGTTGCGTGCCTT-3'). Quantitative real-time PCR (qRT-PCR) analysis was used to count the transgene insertion events and performed using the CFX$96^{\mathrm{TM}}$ Real-Time system (Bio-Rad, Hercules, CA, USA). Each reaction contained $4 \mu \mathrm{L}$ of $3.3 \mathrm{ng} \mu \mathrm{L}^{-1}$ DNA, $1 \mu \mathrm{L}$ of

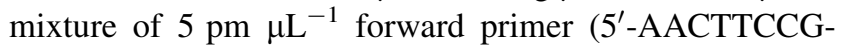
TACCGAGCCGCA- $3^{\prime}$ ) and $5 \mathrm{pm} \mu \mathrm{L}^{-1}$ reverse primer $\left(5^{\prime}-\right.$ TCGTAGGCGTTGCGTGCCTT- $3^{\prime}$ ), $5 \mu \mathrm{L}$ of water and 10 $\mu \mathrm{L}$ of $\mathrm{iQ}^{\mathrm{TM}} \mathrm{SYBR}^{\circledR}$ Green Supermix (Bio-Rad, Ca, USA), for a total volume of $20 \mu \mathrm{L}$. The amplification conditions were as follows: $95^{\circ} \mathrm{C}$ for $3 \mathrm{~min}, 40$ cycles of $10 \mathrm{~s}$ at $95{ }^{\circ} \mathrm{C}$ and $30 \mathrm{~s}$ at $60{ }^{\circ} \mathrm{C}$, then $95{ }^{\circ} \mathrm{C}$ for $10 \mathrm{~s}$, followed by the generation of a dissociation curve by increasing the temperature from 65 to $95^{\circ} \mathrm{C}$, to check amplification specificity. A homozygous transgenic plant already confirmed to have a single Bar gene introgression was used as a single copy control.

\section{SMV infection and investigation of viral resistance}

For virus inoculation, soybean leaves infected with SMV strain G5 were ground in $0.1 \mathrm{M}$ phosphate buffer, $\mathrm{pH} 7.2$ ( $1 \mathrm{~g}$ leaf tissue: $1.5 \mathrm{~mL}$ buffer) with a mortar and pestle, and the resulting suspensions were used as source of inoculums for virus inoculation. Selected seeds of NT, EV and transgenic plants were germinated in soil, and the first leaves of 7-day-old seedling were gently rubbed with Carborundum (Nacalai Tesque, 600 mesh) to wound the surface, then inoculated with a suspension. Inoculated leaves were gently rinsed with water to remove Carborundum (Zeng et al. 2004, 2006). The viral symptoms of inoculated plants were evaluated every week for 4 weeks, and classified as follows: resistance $(\mathrm{R})$, mild mosaic $(\mathrm{mM})$ and mosaic (M) symptoms. The presence of viral symptoms in harvested seeds was also evaluated and classified as follows: clean seed (resistant, R), light seed mottling (mild mosaic, $\mathrm{mM}$ ) and dark seed mottling (mosaic, $\mathrm{M}$ ).

\section{Viral RNA accumulation after viral infection}

For northern blot analysis, total RNA was isolated from viral resistant and susceptible leaves using the Plant RNA Purification Reagent (Invitrogen, USA), according to the manufacturer's instructions. Twenty micrograms of total RNAs were fractionated using $1.2 \%$ denaturing agarose gel electrophoresis and transferred to positively charged nylon membranes (Hybond- $\mathrm{N}^{+}$, Amersham, UK). Hybridization, washing and detection were performed with a digoxigenin (DIG)-labeled DNA probe and a chemiluminescence system, according to the manufacturer's instructions. The DIGlabeled probe was prepared via PCR amplification with $H C$ Pro forward (5'-CACGAAGATGGTAAGGGATG- $\left.3^{\prime}\right)$ and reverse primer (5'-GGTACCCAACTGTCAAGGAT- $\left.3^{\prime}\right)$. The constitutive TUB (5'-TGAGCAGTTCACGGCCATGCT- $3^{\prime} / 5^{\prime}$-CTCGGCAGTGGCATCCTGGT- $3^{\prime}$ ) was used as a control of RNA expression.

For reverse transcriptase PCR (RT-PCR) analysis of plants and seeds, seed samples were prepared by following the method described by Kim and Ku (2006). Total RNA was isolated using the Plant RNA Purification Reagent (Invitrogen, USA) according to the manufacturer's instructions. RT-PCR was carried out using Maxime RTPCR Premix (iNtRon, Korea) according to the manufacturer's instructions. The primer pairs used in the RT-PCR are presented in Table 1 . The constitutive TUB was used as a control of RNA expression.

Quantitative real-time PCR (qRT-PCR) was performed in 96-well plates with the CFX-96 ${ }^{\mathrm{TM}}$ Real-Time system 
Table 1 Gene-specific primers used for reverse transcriptase PCR and quantitative real-time PCR assays

\begin{tabular}{|c|c|}
\hline Gene name & Primer sequence $\left(5^{\prime}\right.$ to $\left.3^{\prime}\right)$ \\
\hline \multirow[t]{2}{*}{ HC-Pro } & Forward: CACGAAGATGGTAAGGGATG \\
\hline & Reverse: GGTACCCAACTGTCAAGGAT \\
\hline \multirow[t]{2}{*}{ Coat protein $(\mathrm{CP})$} & Forward: TTGAGAGATAGAGAGCTGGC \\
\hline & Reverse: TCACATCCCTTGCAGTATGC \\
\hline \multirow[t]{2}{*}{ CI Protein $(\mathrm{CI})$} & Forward: CACAATTGGCTCTGCTGTCA \\
\hline & Reverse: CCCTCAACATTGTGCAGGTT \\
\hline
\end{tabular}

(Bio-Rad, Hercules, CA, USA). First-strand cDNA was synthesized using Superscript ${ }^{\mathrm{TM}}$ II Reverse Transcriptase (Invitrogen) and oligo-dT (Invitrogen), according to the protocols provided in the user manual. The quantity and quality of the synthesized cDNA were determined via a spectrophotometer. Each reaction contained $3 \mu \mathrm{L}$ (3 ng $\left.\mu \mathrm{L}^{-1}\right)$ of cDNA, $0.5 \mu \mathrm{L}\left(10 \mathrm{pm} \mu \mathrm{L}^{-1}\right)$ of each primer and $10 \mu \mathrm{L} \mathrm{SYBR}{ }^{\circledR}$ Premix Ex Taq ${ }^{\mathrm{TM}}$ (Takara) in a total reaction volume of $20 \mu \mathrm{L}$. The PCR conditions were $95^{\circ} \mathrm{C}$ for $3 \mathrm{~min}, 40$ cycles of $10 \mathrm{~s}$ at $95^{\circ} \mathrm{C}, 10 \mathrm{~s}$ at $55^{\circ} \mathrm{C}$, and $20 \mathrm{~s}$ at $72{ }^{\circ} \mathrm{C}$, followed by the generation of a dissociation curve by increasing temperature from $65^{\circ} \mathrm{C}$ to $95^{\circ} \mathrm{C}$, to evaluate amplification specificity. The efficiency and standard deviation of each primer were determined by Bio-Rad CFX manager v1. 6. 541. 1028 on a standard curve generated from a twofold dilution series of one sample at five dilution points for two technical replicates. Baseline and threshold cycle (Ct value) were automatically calculated using the default parameters. The primers and probe used in the qRT-PCR are presented in Table 1. The constitutive TUB was used as an internal control to normalize the amount of RNAs found in soybean plants (Hu et al. 2009).

\section{Investigation of agronomic traits in a greenhouse}

NT and transgenic soybean seeds $\left(\mathrm{T}_{3}\right)$ were planted in seedling tray, and the surfaces of early leaves were inoculated with SMV strain G5. The viral response was evaluated visually so that SMV resistance and susceptibility were classified. NT, SMV-inoculated NT and SMV-inoculated $\mathrm{T}_{3}$ seedlings were then transplanted to large pots and grown in the greenhouse to allow for the evaluation of several agronomic traits, including plant height, number of branches per plant and number of nodes per plant. In addition, the number of pods per plant and the seed weight per plant were also determined to investigate the relative yield of transgenic plants. Statistical analysis was also performed using Excel $T$ Test program to confirm the significance test. Asterisks indicate significant changes compared to NT plants $\left({ }^{*} P<0.05 ;{ }^{* *} P<0.01\right)$.

\section{Results}

Production of soybean transgenic plants with $H C$ Pro using RNAi

To produce transgenic plants containing HC-Pro using RNAi, the forward partial fragment of HC-Pro (306 bp) of SMV strain G7H was amplified via PCR, then recombined into pB7GWIWG2(I) (Fig. 1). The plasmid, pB7GWIWG2(I)-HC-Pro, was constructed and used for the soybean transformation (Fig. 2). The transformation procedure used half-seed explants of the Korean soybean cultivar Kwangan, and followed the modified protocol described by Kim et al. (2013). Half-seed explants of Korean soybean cultivar Kwangan were co-cultivated on CCM (Fig. 2a, left) for 5 days after inoculation (Fig. 2a, right). To induce the shoot formation, explants were placed on SIM without PPT for 14 days and normal shoot formation was observed in this stage (Fig. 2b). Most of primary shoots became necrotic on SIM including $10 \mathrm{mg} \mathrm{l}^{-1}$ PPT during additional 14 days of culture (Fig. 2c). After 4 weeks on SIM, cotyledons were removed completely, and explants were transferred to fresh SEM with $5 \mathrm{mg} \mathrm{l}^{-1}$ PPT (Fig. 2d). At least $4 \mathrm{~cm}$ of elongated shoots was obtained after 4-6 weeks on SEM and transferred to RM for root formation (Fig. 2e). Rooted plantlets were transplanted to the mixture of soil and vermiculite at the rate of $3: 1$ in small pots and acclimated in magenta jar (Fig. 2f). Transgenic plants $\left(\mathrm{T}_{0}\right)$ were transplanted to large pots and grown in a greenhouse (Fig. $2 \mathrm{~g}$ ). To test the herbicide resistance, non-transgenic and transgenic plants were used for leaf painting using $100 \mathrm{mg}^{-1} \mathrm{PPT}$ to test Bar gene expression. After 3-5 days of observation, the leaves of non-transgenic plants were sensitive to PPT and wilted (Fig. 2h, left), whereas transgenic plants were unaffected and resulted in the herbicide resistance (Fig. 2h, right). According to the results of the PPT leaf painting test, about $3 \%$ of transformation efficiency was observed in 5 batches of transformation experiments, and 100-120 soybean seeds were used each time (data not shown). From twenty putative transgenic soybean plants produced, nine healthy and well-growing plants with positive PCR amplifications for four different parts of the T-DNA, as shown in supplementary figure $\mathrm{S} 1$, were selected for use in further experiments.

\section{Confirmation of introduced genes in transgenic plants}

To identify transgenic plants into which the gene had successfully introgressed, genomic DNA was isolated from nine plants and analyzed via PCR. To confirm HC-Pro gene insertion, two parts of T-DNAs (between HC-Pro and 

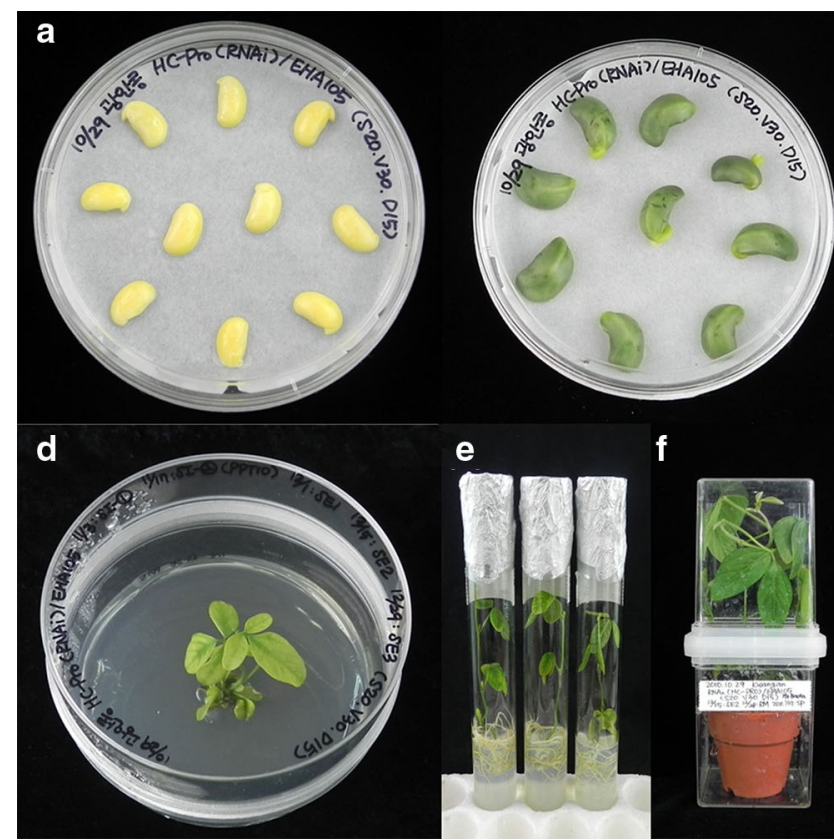

Fig. 2 Agrobacterium-mediated transformation of half-seed explants, and regeneration with $\mathrm{HC}$-Pro using RNAi. a Co-cultivation of halfseed explants after inoculation (left) and at 5 days after inoculation (right). b Shoot induction on SIM without PPT for 14 days. c Shoot induction on SIM with $10 \mathrm{mg}^{-1}$ PPT for another 14 days. d Shoot elongation on SEM with $5 \mathrm{mg} \mathrm{l}^{-1}$ PPT. e Root induction of shoots

intron/between intron and $\mathrm{HC}$-Pro) were amplified with PCR and confirmed. As a result, about $600 \mathrm{bp}$ of PCR amplification was detected in all nine transgenic lines. In addition, $550 \mathrm{bp}$ fragment of Bar gene and $836 \mathrm{bp}$ fragment of DNA between the left border (LB) and Bar gene was amplified via the PCR (Supplementary Fig. S1). Southern blot analysis was carried out using leaf samples of $\mathrm{T}_{2}$ seedlings from transgenic lines \#1 to \#6, to investigate the number of transgene insertions (Fig. 3). The genomic DNA from NT (non-transgenic wild type), EV (transformed with empty vector carrying only Bar) and transgenic plants was isolated and digested using HindIII. After hybridization with Bar probe, low copy of the transgene were detected in lines $\# 1$ to \#5, probably indicating a single insertion, while multiple insertion events were confirmed in line \#6. Quantitative real-time PCR (qRT-PCR) was also performed using the same genomic DNA, to estimate the copy number. As shown in the results of the Southern blot analysis, the copy numbers of all transgenic lines showed similar patterns in the qRTPCR (Supplementary Fig. S2).

\section{Viral disease response of transgenic plants after SMV inoculation}

To confirm the response of transgenic plants to SMV infection, six $\mathrm{T}_{2}$ lines were planted for inoculation with b

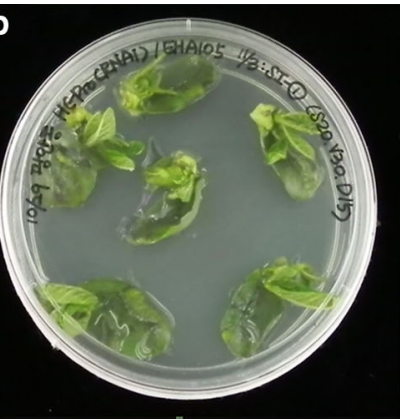

c

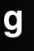

g
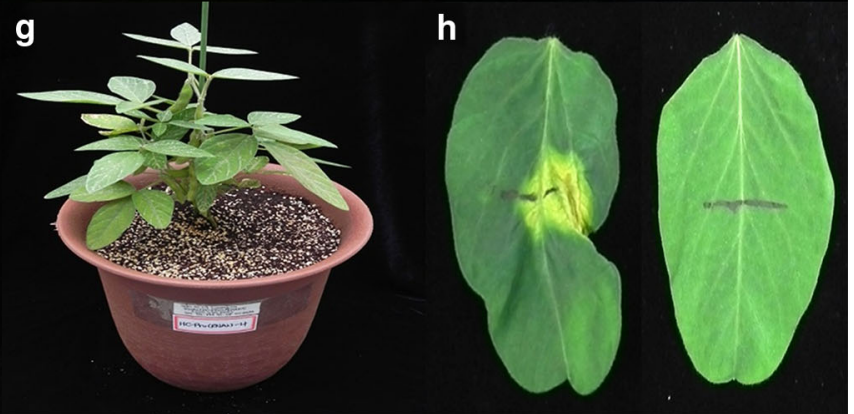

after elongation to at least $4 \mathrm{~cm}$ in length. $\mathbf{f}$ Acclimation of putative transgenic plant in a small pot. g Transgenic plant $\left(\mathrm{T}_{0}\right)$ grown in a large pot. h Painting leaves with herbicide (100 $\left.\mathrm{mg}^{-1} \mathrm{PPT}\right)$ to reveal the sensitivity of non-transgenic plants (left) and resistance of transgenic plants (right)

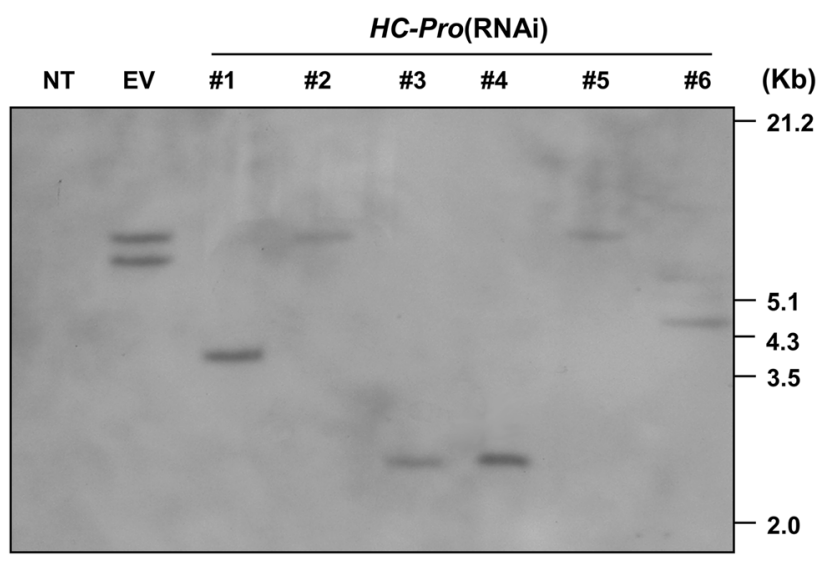

Fig. 3 Detection of insertion events of HC-Pro (RNAi) transgenic soybean. Genomic Southern blot analysis was performed using $15 \mu \mathrm{g}$ of genomic DNAs with HindIII and Bar probe. The DNA molecular size markers are indicated on the right. $N T$ non-transgenic plant, $E V$ transformed with empty vector carrying only Bar; \#1-6, HC-Pro (RNAi) transgenic lines $\left(\mathrm{T}_{2}\right)$

SMV strain G5 due to no availability of G7H strain at the moment. Wild type and transgenic plants were examined for viral symptoms after SMV inoculation. The coleoptiles of 7-day-old seedlings were inoculated and observed for 4 weeks. To evaluate their resistance against SMV, the viral symptoms were visually evaluated and classified into 


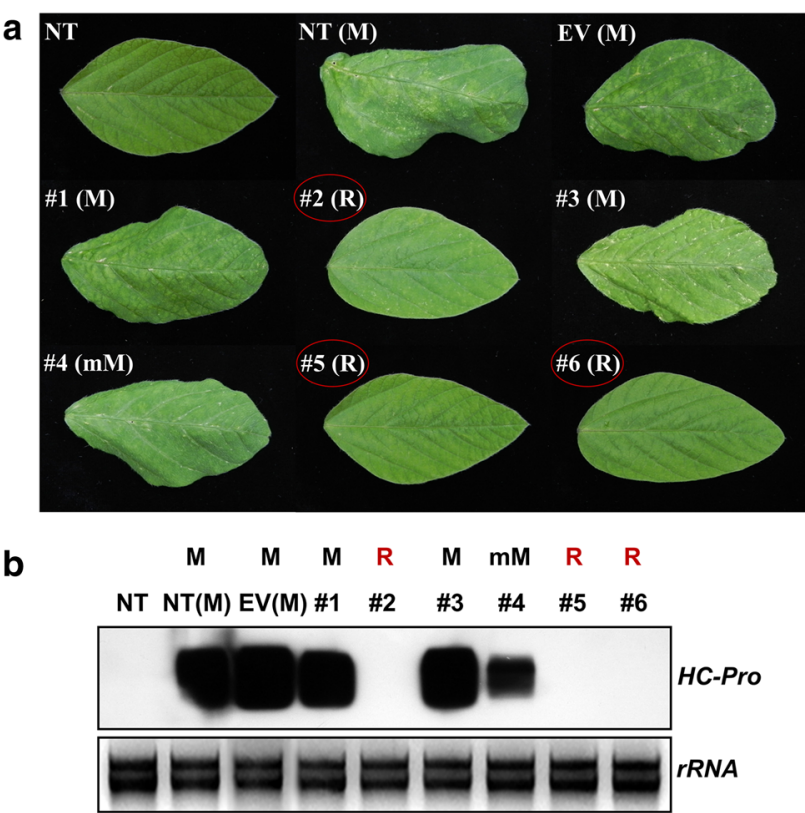

Fig. 4 Response of transgenic plants $\left(T_{2}\right)$ to viral infection. a The seven-day-old first early leaves of non-transgenic and transgenic plants were inoculated with SMV strain G5, and then observed visually for 4 weeks. SMV-inoculated soybean leaves were classified into three groups: viral resistance $(\mathrm{R})$, mild mosaic $(\mathrm{mM})$ symptoms and mosaic (M) symptoms. b Northern blot analysis of transgenic plants after SMV inoculation. The total RNAs were hybridized with the viral $H C$-Pro probe. $N T$ non-transgenic plant, $N T(M)$ nontransgenic plants with SMV inoculation, $E V(M)$ transformed with empty vector carrying only Bar via SMV inoculation, \#1-6 HC-Pro (RNAi) transgenic lines $\left(\mathrm{T}_{2}\right), R$ resistance, $m M$ mild mosaic symptoms, $M$ mosaic symptoms

three subgroups: (1) viral resistance, defined as the absence of symptoms (R); (2) mild mosaic (mM); and (3) mosaic (M). SMV symptoms were observed in the form of light and dark green mosaic patterns and leaf curling on infected leaves. No $\mathrm{T}_{2}$ plants from lines \#2, \#5 or \#6 exhibited any SMV symptoms, indicating the presence of strong viral resistance (R), whereas NT plants and lines \#1, \#3 and \#4 showed mild mosaic $(\mathrm{mM})$ or mosaic (M) symptoms (Fig. 4a). Of the $180 \mathrm{~T}_{2}$ plants that survived the PPT selection, lines \#2 (31/31), \#5 (35/35) and \#6 (37/37) were all highly resistant against SMV. However, all plants from line \#3 were susceptible to SMV, showing the lowest resistance of all tested plants. $\mathrm{T}_{2}$ plants from lines \#1 and \#4 showed $12.2 \%(5 / 41)$ and $25 \%$ (4/16) resistance, respectively. Considering the positive response of PPT selection, this result may not come from the failure of gene introgression.

To verify the heterogeneous response of transgenic plants to SMV infection, the viral HC-Pro accumulation of $\mathrm{SMV}$-inoculated $\mathrm{T}_{2}$ plants was estimated using northern blot analysis (Fig. 4b). Viral RNA accumulation was not detected from three resistant lines (\#2, \#5 and \#6), while
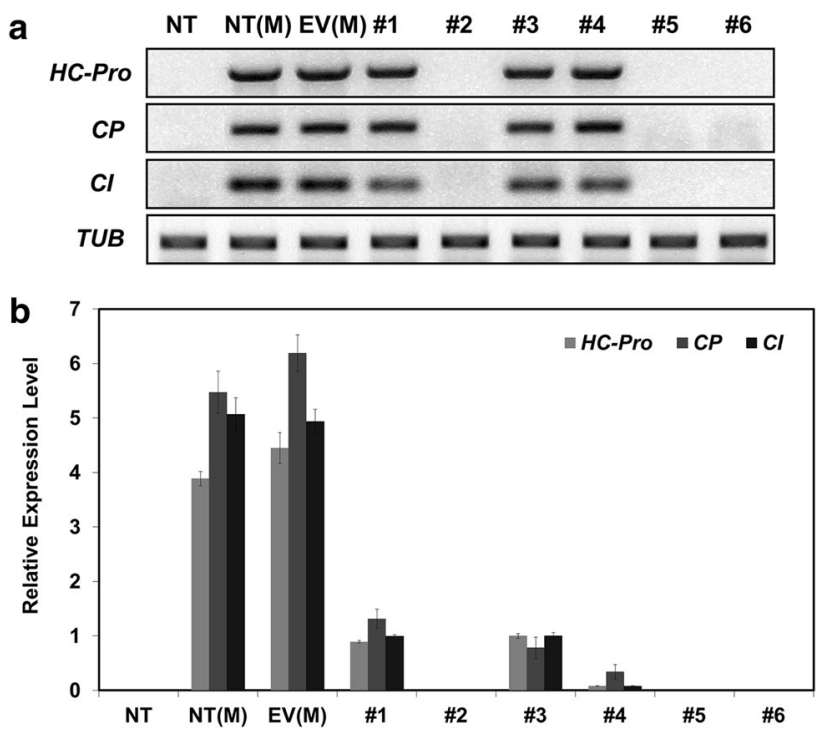

Fig. 5 Expression of potyviral RNA-encoded protein genes in nontransgenic and transgenic plants $\left(\mathrm{T}_{2}\right)$. a Reverse transcriptase PCR. b Quantitative real-time PCR analysis. HC-Pro helper-component proteinase, $C P$ coat protein, $C I$ CI protein, $N T$ non-transgenic plant, $N T(M)$ non-transgenic plants with SMV inoculation, $E V(M)$ transformed with empty vector carrying only Bar via SMV inoculation, \#1-6 HC-Pro (RNAi) transgenic lines $\left(\mathrm{T}_{2}\right)$. Error bars indicate mean \pm standard deviation

NT, EV, and lines \#1, \#3 and \#4 showed viral RNA accumulation when inoculated with SMV. Especially, the leaves of line \#1 and \#4 were non-mosaic pattern but viral RNA was detected from northern blot analysis. Therefore, line \#1 and \#4 were classified as SMV-susceptible lines. To confirm the viral RNA accumulation of other potyviral RNA-encoded protein genes in addition to HC-Pro, the presence of coat protein $(\mathrm{CP})$ and $C I$ protein $(\mathrm{CI})$ genes were investigated on SMV-inoculated $\mathrm{T}_{2}$ plants, using reverse transcriptase PCR and quantitative real-time PCR analysis (Fig. 5). As a result, three SMV-resistant lines (\#2, \#5 and \#6) did not show any viral RNA accumulation, whereas SMV-susceptible lines (\#1, \#3 and \#4) accumulated viral RNA.

\section{Seed morphology after SMV inoculation}

The $T_{3}$ seeds of SMV-inoculated six $T_{2}$ plants were harvested and checked for morphological changes due to the viral infection. The viral symptoms of the seeds were classified into subgroups as follows: (1) clear seed (R); (2) weak brown or black mottled seed $(\mathrm{mM})$; and (iii) dark brown or black mottled seed (M) (Fig. 6a). $\mathrm{T}_{3}$ seeds of lines \#2, \#5 and \#6 were clear and seed coat mottling was not present, indicating that seeds were free of SMV infection. The result seemed to come from the resistance of whole plants. Compared to SMV-resistant seeds, the seeds 


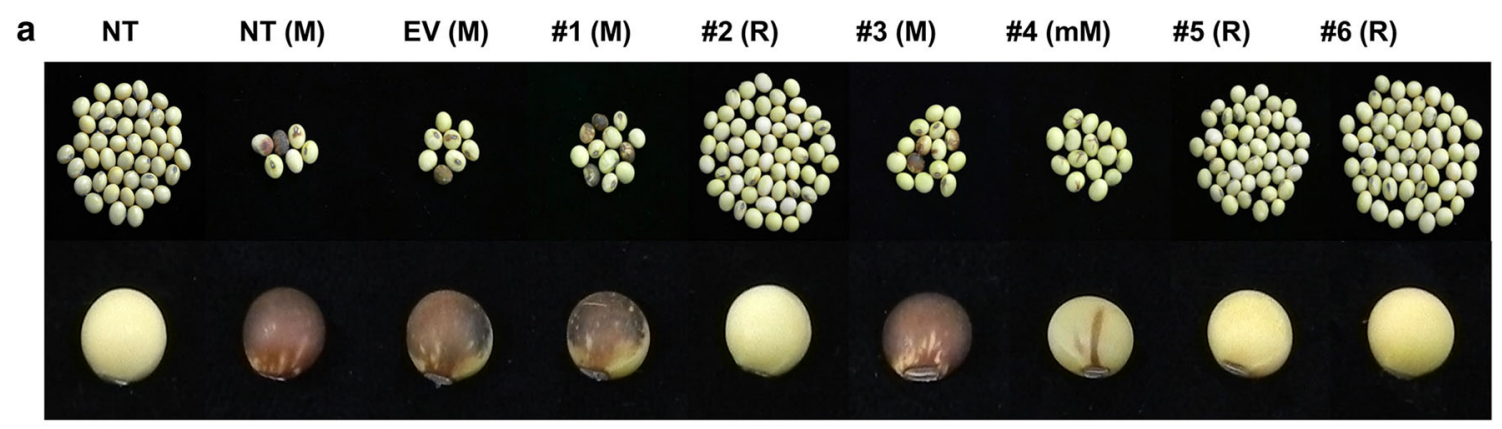

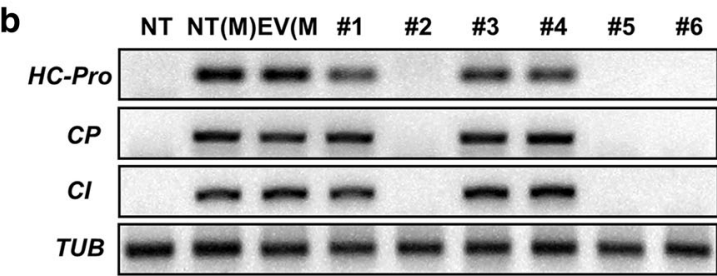

Fig. 6 Morphological changes and viral RNA expression of $\mathrm{T}_{3}$ seeds from SMV-resistant and SMV-susceptible transgenic plants. a Morphological change of $T_{3}$ seeds due to SMV infection. b Potyviral RNA-encoded protein expression of $\mathrm{T}_{3}$ seeds, detected using reverse transcriptase PCR. c Potyviral RNA-encoded protein expression of $\mathrm{T}_{3}$ seeds, detected using quantitative real-time PCR. NT non-transgenic

from lines \#1, \#3 and \#4 had brown or black seed coat mottling with greatly reduced number, indicating that they were infected with SMV.

The resulting seed morphology clearly showed that the virus did not spread to the seeds in SMV-resistant lines, while the seeds of SMV-susceptible lines were greatly influenced by the viral plants. Artificial viral infection of the susceptible plants led to the transmission of the virus from the leaves to seeds, where seed morphology was affected. The harvested seeds were investigated for viral gene accumulation using potyviral RNA-encoded protein genes, including $H C$-Pro, $C P$ and $C I$. Total RNAs were isolated from the $\mathrm{T}_{3}$ seeds of NT, EV, SMV-resistant and SMV-susceptible transgenic plants to confirm the accumulation of viral RNA, using both reverse transcriptase PCR (Fig. 6b) and quantitative real-time PCR (Fig. 6c). Similar accumulation of viral RNA in $\mathrm{T}_{2}$ plants was confirmed using northern blot analysis. $\mathrm{T}_{3}$ seeds from the SMV-resistant lines \#2, \#5 and \#6 did not show any viral RNA accumulation, while the SMV-susceptible lines \#1, \#3 and \#4 revealed the presence of viral RNA, as detected by RT-PCR and quantitative real-time PCR. Among the susceptible lines, line \#4 was relatively mild mosaic symptom than other 2 lines (\#1 \& \#3) in terms of viral RNA accumulation and seed morphological change by

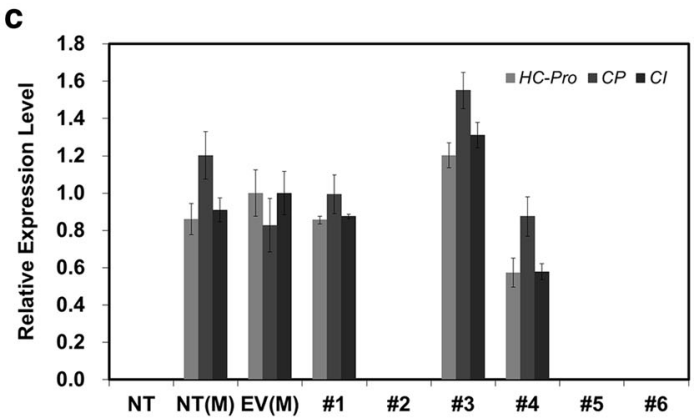

plant, $N T(M)$ non-transgenic plants with SMV inoculation, $E V(M)$ transformed with empty vector carrying only Bar with SMV inoculation, \#1-6 $\mathrm{T}_{3}$ seeds of transgenic lines, $R$ resistance, $m M$ mild mosaic symptoms, $M$ mosaic symptoms, Error bars indicate mean \pm standard deviation

revealing weak brown mottle. All plants from line \#2, \#5 and \#6 were resistant where no mosaic patterns in leaves and seeds were observed.

\section{Yield loss caused by SMV infection}

To investigate the agronomic characteristics of SMV-resistant and SMV-susceptible soybean plants $\left(\mathrm{T}_{3}\right)$ and compare them to those of NT plants, seeds were planted in seedling trays, and 7-day-old seedlings were inoculated with SMV strain G5 (Fig. 7). Eight plants of NT, SMVinoculated NT, SMV-resistant transgenic lines (\#2, \#5 and \#6) and SMV-susceptible transgenic line (\#3) were transferred to large pots after PPT selection, and observed in the greenhouse for the development of symptoms. $T_{3}$ plants of SMV-inoculated transgenic lines \#2, \#5 and \#6 were resistant (R), whereas SMV-inoculated NT plants and SMV-susceptible line \#3 showed SMV symptoms, such as mosaic patterns with curling leaves and growth retardation (Fig. 7a). Agronomic traits, including plant height, number of nodes per plant, number of branches per plant, number of pods per plant and total seed weight, were examined in NT, SMV-resistant transgenic and SMV-susceptible transgenic plants (Fig. 7b-d). With respect to plant height and seed yield, SMV-resistant lines \#5 and \#6 were similar 

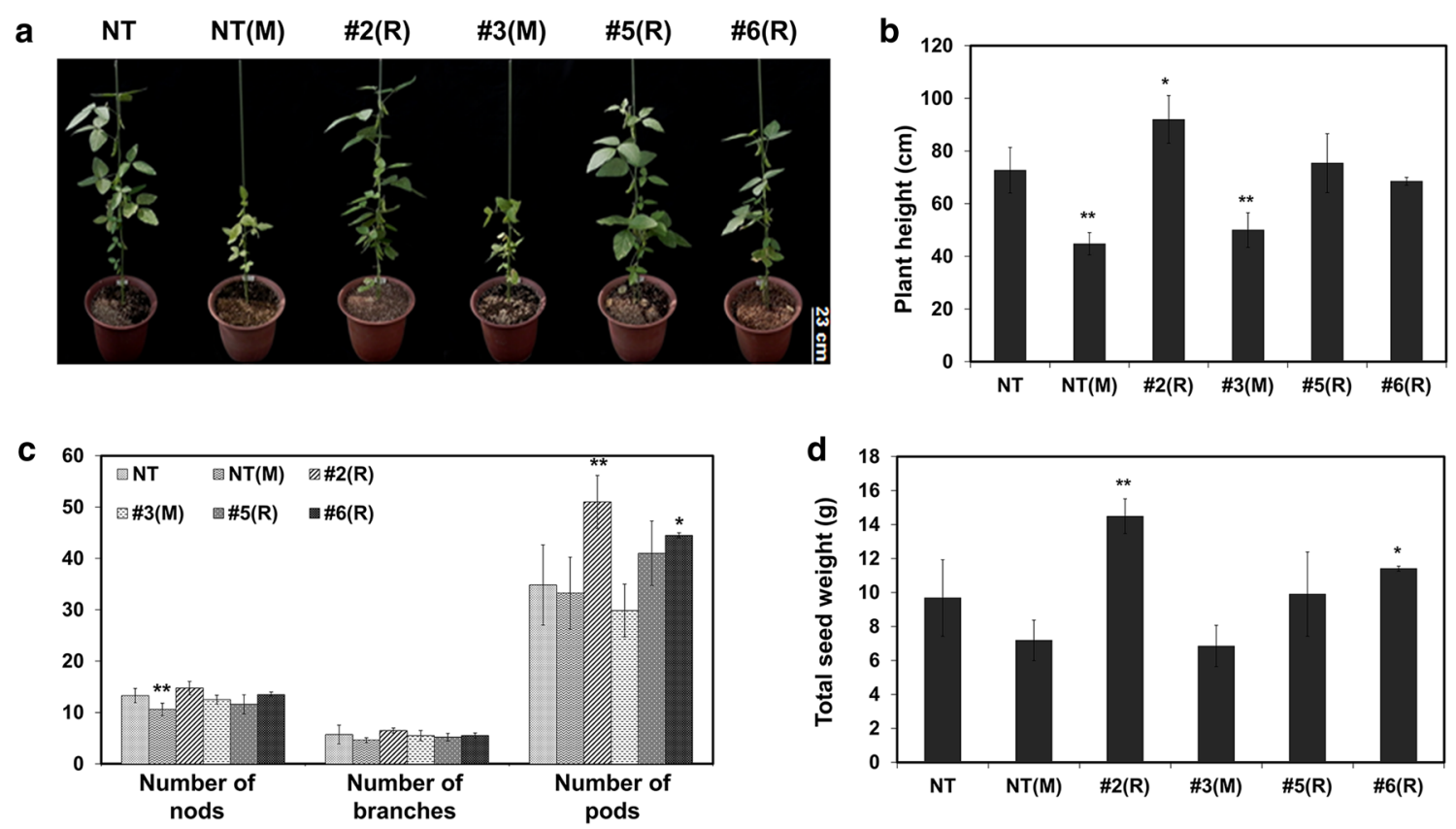

Fig. 7 Agronomic characteristics of $\mathrm{T}_{3}$ transgenic plants after SMV infection in the greenhouse. a Phenotype of non-transgenic (NT), SMV-susceptible non-transgenic [NT(M)], and transgenic plants after 95 days of growth. b-d Agronomic characteristics of NT, NT(M), and transgenic plants. NT non-transgenic plants; \#2, \#3, \#5 and \#6, $H C$ -

to those of NT plants without viral infection, but higher than those of SMV-susceptible plants with statistical significance. In particular, SMV-resistant line \#2 exhibited greater average plant height, pod number and total seed weight with statistical significance. The important agronomic traits of SMV-resistant lines \#2, \#5 and \#6 were generally similar to, or more favorable than, those of normal wild type plants, even under strong artificial SMV infection. However, SMV-susceptible line \#3 exhibited a significantly lower average plant height and seed yield than NT and SMV-resistant lines (Fig. 7c, d).

\section{Discussion}

Agrobacterium-mediated transformation system, based on the cotyledonary-node $(\mathrm{CN})$ method, is widely used for the improvement of soybeans with agriculturally important traits (Hinchee et al. 1988). In spite of our efforts to repeat same condition of transformation method publicly reported, our previous experiment did not produce stable transgenic plants of Korean cultivars (Lee et al. 2006). However, adopting the half-seed method (Paz et al. 2006) with the minor modification of adding thiol compounds successfully produces transgenic Korean soybean cultivars. The main obstacle in producing transgenic plants of Korean cultivars was the severe browning that developed
Pro(RNAi) transgenic lines $\left(\mathrm{T}_{3}\right), R$ resistance, $m M$ mild mosaic symptom, $M$ mosaic symptom, Error bars indicated mean \pm standard deviation. Asterisks indicate significant changes compared to NT plants $\left.{ }^{*} P<0.05 ;{ }^{* *} P<0.01\right)$

during the early stages of the transformation procedure. Because we hired extra strength of Agro-infection pressure to increase transformation ratio via dipping with high concentration of Agrobacterium solution, and treating with sonication and vacuuming during initial co-cultivation. By adding a thiol compound, such as L-cysteine, dithiothreitol (DTT) and sodium thiosulfate, we could prevent this early enzymatic browning and cell damage. It is well-known that thiol compounds used in co-cultivation increase A. tumefaciens infection and T-DNA transfer by inhibiting the activity of pathogen- and wound-response enzymes such as peroxidases and polyphenol oxidases in the cotyledonarynode region (Olhoft et al. 2003). Considering the results of our previous experiment, it is very clear that adding the thiol compound contributed significantly to the production of successful transgenic plants of the Korean cultivar. In this study, we used a modified half-seed method to transform a Korean cultivar, with a transformation efficiency of about $3 \%$. This is similar to the efficiency rate reported by Gao et al. (2015), but lower than that of our previous experiment (Kim et al. 2013). A transformation efficiency of about $3 \%$ is not highly efficient, but is enough to produce more than 20 transgenic plants from 500 explant seeds. We believe that $2-30$ transgenic plants are enough to study any unknown gene function or test any gene for association with agronomic traits, as was done in our study. Despite using the same transformation protocol, efficiency 
can change from experiment to experiment. It is more important that a method allows one to consistently obtain successful transformants, regardless of the personal skill of an individual researcher. In that respect, the half-seed method is suitable for use by inexperienced researchers. Wounding one-day-old germinating seeds does not require a complicated procedure or refined techniques. In addition, the half-seed method is less time-consuming.

In our previous RNAi-based study of SMV-resistant soybean plants with $S M V$-CP (Kim et al. 2013), most of the transgenic lines were found to be SMV-susceptible, indicating that a viral protein (HC-Pro) blocks the production of siRNAs to suppress gene silencing by the host plant. Due to its limitation of $S M V-C P$ RNAi for SMV resistance in soybean, HC-Pro was used to produce strong and complete resistance. Recently, Gao et al. (2015) reported results similar to ours, obtained by producing SMV-resistant soybean plants of Chinese cultivars using an HC-Pro gene fragment from SMV SC3 strain via RNAi. One small difference is the presence of viral transcript after the SMV inoculation of transgenic plants; in our study, no accumulation of viral transcript was detected in resistant $T_{2}$ plants and $\mathrm{T}_{3}$ seeds, via either northern blot analysis or reverse transcriptase PCR and quantitative real-time PCR analysis; however, a gradual decrease or low level of viral transcript accumulation was detected in $\mathrm{T}_{1}$ plants via $\mathrm{qRT}-\mathrm{PCR}$ during their study. This difference may be the result of using biological materials at different stages and generations, or differences between the plants and seeds used. However, it is very clear that three resistant lines produced during this study were free of viral transcript, even under the sensitive analytic methods used. Among the six transgenic lines tested in this study, three classes of disease response were identified; resistant, mild mosaic and mosaic as susceptible. Northern blot analysis on $\mathrm{T}_{2}$ plants clearly showed the different level of viral RNA accumulation by different disease responses. Level of viral RNA accumulation is well matched with phenotypical disease susceptibility (Fig. 4). The result might come from the positional effect of transgene. It is very common to observe various level of expression of transgene not only in transgenic plants but in animal due to the position effect (Mlynárová et al. 1994; Matzke and Matzke 1998; Halweg et al. 2005).

In light of all the evidences, the application of RNAi using HC-Pro seems to confer much stronger viral resistance than any previous method. Clear difference between the major yield components of resistant and susceptible lines in later generations indicates that SMV infection has a significant effect on both plants and seeds. SMV resistance using RNAi can have a huge impact on yield increase or at least the stability of a certain level of yield, by protecting soybeans from severe SMV infection.
RNAi is becoming increasingly important to the genetic engineering of plants for crop improvement. Though it was only discovered recently, it functions as a basic mechanism of gene regulation in higher organisms, including plants. During various cellular procedures, a plant requires a method of decreasing gene expression for a number of reasons, such as defense against the viral invasion of a plant cell. In terms of genetic engineering, it is interesting to note that we have long used RNAi to create new agronomic or industrial traits, though unknowingly (Jagtap et al. 2011; Frizzi and Huang 2010). More and more genetically engineered crops produced using RNAi are being registered by global companies with special traits ranging from virus resistance to quality control. The RNAi of plant endogenous genes is very useful for changing a plant's oil composition to improve its fatty acid profile, reducing lignin for better quality, decreasing the potential for harmful chemicals to form during food processing, and reducing susceptibility to bruising (https://www.aphis.usda. gov/aphis/home).

In this study, we could produce transgenic soybean lines with viral resistance via the RNAi of HC-Pro. This is much consolidated result than the previous report. In future work, an extensive field test is scheduled to take place, which will test these transgenic plants under natural conditions of SMV occurrence.

Acknowledgments This work was supported by the Next-Generation BioGreen 21 Program (Code PJ011150), Rural Development Administration, and Korea Institute of Planning and Evaluation for Technology in Food, Agriculture, Forestry and Fisheries (Code 112124-5), Republic of Korea.

\section{References}

Cho EK, Goodman RM (1979) Strains of soybean mosaic virus: classification based on virulence in resistant soybean cultivars. Phytopathology 69:467-470

Di R, Purcell V, Collins GB, Ghabrial SA (1996) Production of transgenic lines expressing the bean pod mottle virus coat protein precursor gene. Plant Cell Rep 15:746-750

Frizzi A, Huang S (2010) Tapping RNA silencing pathways for plant biotechnology. Plant Biotechnol J 8:655-677

Furutani N, Hidaka S, Kosaka Y, Shizukawa Y, Kanematsu S (2006) Coat protein gene-mediated resistance to soybean mosaic virus in transgenic soybean. Breed Sci 56:119-124

Gagarinova AG, Babu M, Poysa V, Hill JH, Wang A (2008) Identification and molecular characterization of two naturally occurring Soybean mosaic virus isolates that are closely related but differ in their ability to overcome Rsv4 resistance. Virus Res 138:50-56

Gao L, Ding X, Li K, Liao W, Zhong Y, Ren R, Liu Z, Adhimoolam $\mathrm{K}$, Zhi H (2015) Characterization of Soybean mosaic virus resistance derived from inverted repeat-SMV-HC-Pro genes in multiple soybean cultivars. Theor Appl Genet 128:1489-1505

Gunduz I, Buss GR, Chen P, Tolin SA (2004) Genetic and phenotypic analysis of Soybean mosaic virus resistance in PI 88788 soybean. Phytopathology 94:687-692 
Halbert SE, Irwin ME, Goodman RM (1981) Alate aphid (Homoptera: Aphididae) species and their relative importance as field vectors of soybean mosaic virus. Ann Appl Biol 97(1):1-9

Halweg C, Thompson WF, Spiker S (2005) The Rb7 matrix attachment region increases the likelihood and magnitude of transgene expression in tobacco cells: a flow cytometric study. Plant Cell 17:418-429

Hayes AJ, GR MA, Buss GR, Maroof MAS (2000) Molecular marker mapping of Rsv4, a gene conferring resistance to all known strains of soybean mosaic virus. Crop Sci 40(5):1434-1437

Hill JH, Lucas BS, Benner HI, Tachibana H, Hammond RB, Pedigo LP (1980) Factors associated with the epidemiology of soybean mosaic virus in Iowa. Phytopathology 70:536-540

Hinchee MAW, Connor-Ward DV, Newell CA, McDonnell RE, Sato SJ, Gasser CS, Fischhoff DA, Re DB, Fraley RT, Horsch RB (1988) Production of transgenic soybean plants using Agrobacterium-mediated DNA transfer. Nat Biotechnol 6:915-922

Hobbs HA, Hartman GL, Wang Y, Hill CB, Bernard RL, Pedersen WL, Domier LL (2003) Occurrence of seed coat mottling in soybean plants inoculated with Bean pod mottle virus and Soybean mosaic virus. Plant Dis 87:1333-1336

Hu R, Fan C, Li H, Zheng Q, Fu YF (2009) Evaluation of putative reference genes for gene expression normalization in soybean by quantitative real-time RT-PCR. BMC Mol Biol 10:93

Jagtap UB, Gurav RG, Bapat VA (2011) Role of RNA interference in plant improvement. Naturwissenschaften 98:473-492

Karimi M, Inze A, Depicker A (2002) Gateway $^{\mathrm{TM}}$ vectors for Agrobacterium-mediated plant transformation. Trends Plant Sci 7(5):193-195

Kasschau KD, Carrington JC (2001) Long-distance movement and replication maintenance functions correlate with silencing suppression activity of potyviral HC-Pro. Virology 285:71-81

Kim KI, Ku JH (2006) Isolation of high quality RNA from seeds of the Mungbean (Vigna radiata). Kor J Crop Sci 51(S):274-276

Kim HJ, Kim MJ, Pak JH, Jung HW, Choi HK, Lee YH, Baek IY, Ko JM, Jeong SC, Pack IS, Ryu KH, Chung YS (2013) Characterization of SMV resistance of soybean produced by genetic transformation of $S M V-C P$ gene in RNAi. Plant Biotechnol Rep 7:425-433

Lee KJ, Seo JK, Lee HY, Jeon EH, Shin SH, Lee JH, Kim DH, Ko JM, Hahn WY, Baek IY, Oh BJ, Chung YS (2006) Optimization of genetic transformation conditions for Korean soybean cultivars. Kor J Life Sci 16(2):289-296

Lim SM (1985) Resistance to soybean mosaic virus in soybeans. Phytopathology 75:199-201

Lim HS, Ko TS, Lambert KN, Kim HG, Korban SS, Hartman GL, Domier LL (2005) Soybean mosaic virus helper componentprotease enhances somatic embryo production and stabilizes transgene expression in soybean. Plant Physiol Biochem 43:1014-1021

Matthew L (2004) RNAi for plant functional genomics. Comp Funct Genom 5:240-244

Matzke AJM, Matzke MA (1998) Position effects and epigenetic silencing of plant transgenes. Curr Opin Plant Biol 1:142-148

Meurer CA, Dinkins RD, Collins GB (1998) Factors affecting soybean cotyledonary node transformation. Plant Cell Rep 18:180-186

Mlotshwa S, Verver J, Sithole-Niang I, Prins M, Kammen AV, Wellink J (2002) Transgenic plants expressing HC-Pro show enhanced virus sensitivity while silencing of the transgene results in resistance. Virus Genes 25(1):45-57

Mlynárová L, Loonen A, Heldens J, Jansen RC, Keizer P, Stiekema WJ, Nap JP (1994) Reduced position effect in mature transgenic plants conferred by the chicken Lysozyme matrix-associated region. Plant Cell 6:417-426

Olhoft PM, Flagel LE, Donovan CM, Somers DA (2003) Efficient soybean transformation using hygromycin B selection in the cotyledonary-node method. Planta 216:723-735

Paz MM, Martinez JC, Kalvig AB, Fonger TM, Wang K (2006) Improved cotyledonary node method using an alternative explant derived from mature seed for efficient Agrobacterium-mediated soybean transformation. Plant Cell Rep 25:206-213

Plisson C, Drucker M, Blanc S, German-Retana S, Gall OL, Thomas D, Bron P (2003) Structural characterization of HC-Pro, a plant virus multifunctional protein. J Biol Chem 278:23753-23761

Rahman M, Ali I, Husnain T, Riazuddin S (2008) RNA interference: the story of gene silencing in plants and humans. Biotech Adv 26:202-209

Roth BM, Pruss GJ, Vance VB (2004) Plant viral suppressors of RNA silencing. Virus Res 102:97-108

Seo JK, Lee HG, Kim KH (2009) Systemic gene delivery into soybean by simple rub-inoculation with plasmid DNA of a Soybean mosaic virus-based vector. Arch Virol 154:87-99

Soitamo AJ, Jada B, Lehto K (2011) HC-Pro silencing suppressor significantly alters the gene expression profile in tobacco leaves and flowers. BMC Plant Biol 11:68

Steinlage TA, Hill JH, Nutter FW Jr (2002) Temporal and spatial spread of soybean mosaic virus (SMV) in soybeans transformed with the coat protein gene of SMV. Phytopathology 92:478-486

Tenllado F, Llave C, Díaz-Ruíz JR (2004) RNA interference as a new biotechnological tool for the control of virus diseases in plants. Virus Res 102:85-96

Zeng P, Vadnais DA, Zhang Z, Polacco JC (2004) Refined glufosinate selection in Agrobacterium-mediated transformation of soybean [Glycine max (L.) Merrill]. Plant Cell Rep 22:478-482

Zheng C, Chen P, Gergerich R (2006) Genetic analysis of resistance to soybean mosaic virus in J05 soybean. J Hered 97(5):429-437 